https://doi.org/10.48009/1_iis_2007_108-114

\title{
ADVISORY BOARD: EXPERIENCE AND STATUS REPORT
}

\author{
Adel Fergany, Slippery Rock University, adel.fergany@sru.edu \\ Sam Thangiah, Slippery Rock University, sam.thangiah@sru.edu
}

\begin{abstract}
Academia and Industry are locked into a producer/consumer relationship: academia seeks to educate and prepare students to become active players in the labor force. Industry, on the other hand, wants to ensure that such students are getting the "right" kind of education and training in preparation for the job at hand.

The Computer Science Department, Slippery Rock University, has a very active advisory board since Fall 2000. This paper presents the department's experience with its advisory board, its history and guidelines for establishing similar boards. This paper also discusses the mutual benefits and typical activities of a successful advisory board.
\end{abstract}

Keywords: Advisory Board, Assessment.

\section{INTRODUCTION}

Academia and Industry are locked into a producer/consumer relationship: academia seeks to educate and prepare students to become active players in the labor force. Industry, on the other hand, wants to ensure that such students are getting the "right" kind of education and training in preparation for the job at hand. Thus, cooperation between industry and academia should be expected and encouraged from both sides in order to develop a true partnership for the benefit of the educational process. Advisory boards, which are formed from a select group of industry leaders, can work both ways: academicians advising industry leadership about new trends in the educational domain, and industry providing feedback on the quality and effectiveness of the educational process, thus enhancing the process of assessment and continuous improvement.

An educational institution may benefit from an advisory board in many different ways:

- Help setting general requirements and goals of an educational program or specific course of study;
- Provide short-term, or long-term, on-the-job training for students, thus complementing the classroom subject matter;

- Advising students regarding the transition from the educational to professional environment;

- Assessing the quality of the educational process based on the performance of students during the short-term, or long-term, on-the-job training.

That is, of course, in addition to any philanthropic or other forms of promotion that industry may contribute to educational institutions.

The Computer Science Department, Slippery Rock University (SRU), has a rich and long experience with advisory boards. In this report, we provide a history of our experience with advisory boards, the spectrum of activities of our advisory board, and our assessment of the benefits and effectiveness of such collaboration for the department and the students.

\section{HISTORY OF ADVISORY BOARD AT COMPUTER SCIENCE DEPARTMENT, SRU}

The Computer Science Department Advisory Board was initiated in Fall 2000 by Dr. Sam Thangiah, who continues to be the coordinator and the convener of this important function. The board was established in order to seek feedback from people out in the field and to ensure that the department curriculum was keeping up with the changes outside of academia.

The members of the board were selected based on their area of expertise. Initially there were ten board members, including two who were alumni of the department. When choosing alumni we ensured that they had been out in the field for more than five years, as this gave them a better perspective on the mission of the department and also enabled them of using their education to attain enough experience in the real world. The board meets twice a year, once in the fall and the other in spring. In addition to the meetings, the members of the board take part in the speaker series in various classes taught in the department. The board members are also actively involved in the Industry Awareness Night and Job Shadow Day held each spring. 


\section{ADVISORY BOARD SPECTRUM OF ACTIVITIES}

Typically, the Advisory Board of the Computer Science Department, Slippery Rock University, meets twice every year, once in the fall and once in the spring semester. The Advisory Board members also actively participate in the Industry Awareness Night and Job Shadow Day, which are held each spring.

\section{The Board of Visitors Fall Meeting}

The fall meeting usually takes place at the SRU campus in the second half of the fall semester, and usually takes half a day. This meeting is devoted for an open dialogue between the faculty and industry leaders regarding the educational process. The fall meeting usually consists of presentations by faculty and industry leaders: faculty present on proposed enhancements to the programs and course content; industry leaders provide their assessment of previous and newly proposed enhancements. The presentations are followed by discussions regarding the issues that were raised, together with any new ideas that may surface. The meeting concludes with a working lunch to maximize the benefits of the meeting. A typical agenda of the fall meeting is as follows:

\section{Department of Computer Science Slippery Rock University of Pennsylvania Board of Visitors Meeting Pennsylvania Room, North Hall}

November 17, 2006

\section{Program for the Day}

\begin{tabular}{|c|c|c|c|c|}
\hline 9:00 & AM & 9:30 & AM & Arrival \\
\hline 9:30 & $\mathrm{AM}$ & $-10: 30$ & Noon & Meeting \\
\hline 10:45 & $\mathrm{AM}$ & - $11: 45$ & $\mathrm{AM}$ & Tour of ATS \\
\hline & & \multicolumn{3}{|c|}{ Hall, Faculty Presentations } \\
\hline & Noon & - $\quad 1: 00$ & PM & Lunch \\
\hline & $\mathrm{PM}$ & $\ldots$ & $\begin{array}{l}\text { Other } \\
\text { erest }\end{array}$ & ems of \\
\hline
\end{tabular}

\section{Agenda for the Meeting}

1. Mutual Introduction

a. Dr. Bruce Russell, Dean, College of Business, Information and Social Sciences

b. Dr. David Valentine, Chair, Computer Science Department
2. Chairperson's Report

3. Matters of Current Interest

a. Industry Awareness Night/Job Shadow Day

b. Student assessment of internships

c. Affiliation agreement (for internships)

4. Tour of the Advance Science and

Technology Hall

5. Faculty Presentations and Discussions

\section{SVG - Scalable Vector Graphics David Dailey}

SVG is a web standard for client-side graphics. The graphics are described as vectors rather than bitmaps, hence avoiding large downloads of files. SVG is an XML language endorsed by the W3C.

The graphics are scalable and zoomable, rendered in whatever precision the display device can handle. SVG is cross-browser compatible with the majority of the W3C specification working currently in IE, FireFox, and Opera. Interest, as measured by Google web sites discussing the topic, has grown ten-fold in two years, with SVG moving ahead of FORTRAN, but still behind Visual Basic in terms of its topical coverage on the Web. It shares a Document Object Model having much in common with HTML, coexists with HTML or stands by itself (e.g., in mobile devices), and is manipulated client-side by JavaScript, meaning that graphics may be built dynamically in the browser. An overview of the language and several examples will be discussed.

\section{Programming in Alice Paul Mullins}

A comparison of typical programs completed by students in Introduction to Programming using $\mathrm{C}++$ and Alice.

\section{The Board of Visitors Spring Meeting}

The spring meeting takes place at the Regional Learning Alliance, a learning center that is located close to Pittsburgh and is a short driving distance for most of the advisory board members. The spring meeting is similar to the fall meeting, except that presentations are made by undergraduate students. This allows the industry leaders to gauge the types of projects that the students are involved in during the course of their studies. In addition, it gives the industry leaders an opportunity to interact with the 
students directly. A typical agenda for the spring meeting would be as follows:

\section{Department of Computer Science Slippery Rock University of Pennsylvania Board of Visitors Meeting Regional Learning Alliance Room 2113 \\ http://www.regionallearningalliance.com/directions.h tml}

April 21, 2006

Program for the Day

\begin{tabular}{|c|c|c|c|c|}
\hline 9:00 & AM & 9:30 & AM & Arrival \\
\hline 9:30 & AM & - $10: 20$ & $\mathrm{AM}$ & Student \\
\hline & & & \multicolumn{2}{|c|}{ Presentations } \\
\hline & AM & $12: 00$ & Noon & Meeting \\
\hline & Noon & $1: 00$ & PM & Lunch \\
\hline & PM & $\ldots$ & \multicolumn{2}{|c|}{ Other items of } \\
\hline
\end{tabular}

interest

\section{Agenda for the Meeting}

1. Mutual Introduction

a. Dr. Bruce Russell, Dean, College of Business, Information and Social Sciences

b. Dr. David Valentine, Chair, Computer Science Department

2. Student Presentations

3. Chairperson's Report

4. Matters of Current Interest

a. Curricular changes

b. Report on the Advanced Science and Technology Hall

c. Report on the high school contest

d. Computer Literacy

e. Internship/Work Co-Op Program

f. SAP training and other "credentials"

\section{Students’ Presentations}

\section{Shape Based Insertion Techniques \\ Corey Callihan and Andrew Beers}

This project was done as a Heuristic insertion method for use with a Multiple Depot Vehicle Routing Problem (MDVRP). It has been observed in the resulting solutions created by the standard MDVRP, there is a pattern to be seen by the individual truck routes. This pattern is petal shaped (resembling the shape of a flower petal) with the depot the trucks are operating from at the center. These shapes can vary in size and radius, but in almost all cases of the best solutions, fall into this petal type form.

The fact that the truck route solutions tend towards these petal shapes is what spawned the idea for our project, which uses the direct insertion of shipments to trucks based upon pre-positioned geometric shapes.

This project, Shape Based Insertion Heuristics, is a competitive vehicle routing system based upon common geometric shapes. The Shape Insertion package allows for the use of multiple types of shapes, i.e. Squares, circles, triangles, polygons, etc, to be overlaid on the grid containing the shipment locations and the depot locations. Each shape can be seen to represent an individual truck, and that truck will run from the depot to which it is closest. Shipments are then assigned to the individual shapes based upon their proximity or containment therein. If a shipment is contained within a particular shape, it is automatically assigned to that corresponding truck. Otherwise the program will determine which shape the shipment is closest to and assign the shipment to that particular truck. The program will generate more shapes (trucks) as necessary to be sure that all shipments are handled. The algorithm was implemented on multiple data sets and a simple random movement optimization algorithm, and was able to get competitive results with the standard MDVRP assignment methods. The results indicated by our Shape Based Insertion method for vehicle routing shipment insertion are as competitive as other methods implemented in literature. 


\section{Tabu Search for Vehicle Routing Problems}

\section{Joshua Petry and Anthony Wijeysooriya}

A simple vehicle routing problem (VRP) consists of assigning various shipments to trucks within a central depot. The goal to be reached in solving a VRP is to minimize the total cost, with a concern to the number of trucks and the total distance traveled by them. There are various constraints for this problem, such as the travel time and capacity of a truck.

A simple VRP can be expanded in many ways. In this research, we look at one particular case - a multidepot vehicle routing problem with pickup and delivery and time windows (MDVRPPDTW). The constraints added to this specific problem include having more than one depot available, in which each contain trucks capable of both picking up and delivering shipments to customers, where each shipment must be serviced within a defined time-frame.

If the most effective method is required, simply too much processing time would be required in obtaining it, in such that it most likely will outweigh the cost of actually finding it. Various heuristic methods are used to find a solution most near the best, in a time-efficient manner. This research project involved using a metaheuristic method known as Tabu Search. Tabu Search is an intelligent algorithm that inspects less effective orderings of the various truck routes, to attempt to find a more cost-efficient ordering. Various parameters were set, and analyzed, to develop solutions to MDVRPPDTW that are more efficient than those obtained through standard heuristics.

\section{B12 Robot Graphical Interface}

\section{Kevin Sobczak, Anthony Wijeysooriya, Stephanie Kasenter, Samuel Rummel, Brian Turner}

The B12 Robot is controlled by a Motorola 68000 processor and utilizes several motors and sonars for movement and obstacle detection. Several layers of code have been designed for the Motorola 68000 assembly code to allow the robot to be controlled via simple C Code commands. The newest addition to this project is the graphical interface. The interface was built using Borland $\mathrm{C}++$ Builder and utilizes the serial connection to the robot to obtain information on sonar readings, rotation, translation, dead-reckoning, battery

voltage, and motor status. All information is then presented in a graphical interface to allow the user to monitor many aspects of the B12. For the interface to obtain this information several changes to the assembly code and C Code layers had to be made. In addition to viewing the status locally there is also a web interface that allows monitoring over the internet. The interface also supports uploading of files to be executed along with manual control of the robot. This project has been ongoing but is finally approaching completion with the current group who have been working together for the past 14 weeks.

\section{Industry Awareness Night}

Each spring the department hosts the Industry Awareness Night, which usually takes place on an evening in February, at the Regional Learning Alliance at Cranberry Woods, Pennsylvania. It is devoted for the benefit of the students who are close to graduation. The industry leaders present on a wide range of topics covering a spectrum of activities in the work place, the difference between educational and professional life, the employers' expectations, preparation of a resume, interviewing techniques, and other issues of interest. The students may also get the opportunity to listen to some of their former classmates, who have already joined the labor force, talking about their own experience in transitioning to the real world. But, most importantly, the students get their first exposure on the art of networking with industry leaders and talk to them one-on-one, in a friendly environment around the dinner tables.

The following is the agenda of the Industry Awareness Night, Spring 2006, which shows the spectrum of activities that take place in such a meeting: 


\section{Industry Awareness Night 2006 \\ February 8, 2006 \\ 5:00 PM to 8:30 PM \\ Regional Learning Alliance \\ Cranberry Woods, PA \\ http://www.regionallearningalliance.com/directions.h $\underline{\mathrm{tml}}$}

\section{Master of Ceremonies: Dr. David Valentine}

A. Welcome and Opening Remarks

Dr. Bruce Russell, Dean, College of

Business, Information and Social

Sciences; Dr. David Valentine, Chair,

Department of Computer Science

B. Introduction to Industry Representatives

C. Dinner

D. Presentations: (10 - 12 minutes each)

- Ms. Megan Webberking - The Future Is Always Beginning Now

- Ms. Erin Baker - Getting Your Feet Wet in the Professional World ... with Internships!

- Ms. Lori Jashinski \& Ms. Pam Babbit

- Interview Techniques

- Mr. Grant Liddle - Top 10 Ways NOT to Get Hired

- Mr. Jay Audino - Tips Toward Landing that First Job

- Mr. Barry Skirble - Optimize IT

- Mr. Julian Anantarow - The Relevance of Systems in Banking

- Mr. Steven Park - Time Management

- Mr. Matthew Piroch - Conclusion

E. One-On-One: Resumes

F. Wrap Up - Dr. Sam R. Thangiah

Industry Panel:

- Mr. Julian Anantarow; Mellon Global Financial

- Mr. Jay Audino; Bayer

- Ms. Pam Babbit; McKesson Automation Inc.

- Ms. Erin Baker; Regional Internship Center of SWPA

- Ms. Christine Hebor; GlaxoSmithKline

- Ms. Lori Jashinski; McKesson Automation Inc.

- Mr. Grant Liddle; McKesson Automation Inc.

- Mr. Mathew Maricone; Highmark Life \& Casualty Group

- Mr. Steve Park; Highmark Life \& Casualty Group

- Mr. Matthew Piroch; Highmark Life \& Casualty Group
- Ms. Emilie Ray; McKesson Automation Inc.

- Mr. Kevin Reily; Highmark Life \& Casualty Group

- Mr. Barry Skirble; Aethon Inc.

- Ms. Megan Webberking; Real-Time Outbreak and Disease Surveillance Laboratory, Univ. of Pittsburgh

\section{Faculty:}

- Dr. Bruce Russell, Dean

- Dr. David Valentine

- Dr. Michael Conlon

- Dr. Adel Fergany

- Prof. Frank Hulick

- Prof. Patricia Joseph

- Dr. Sharadchandra W. Joshi

- Dr. Sam R. Thangiah

The Industry Awareness Night is very well appreciated, both by students and Industry leaders. Here is some of the feedback we received:

Students' Feedback:

The event was very helpful. It gave me insight into exactly what kind of jobs I can look forward to in the market. It also gave me good tips and information on how to obtain one of these jobs.

... the representatives from the organizations helped us by giving tips on our résumé's and how to prepare for an interview, what criteria they look at when they interview etc.

... After all the advice that the industry representatives gave out tonight, I'll definitely approach my upcoming internship with a different view than the last.

I especially liked how the people from McKesson focused the majority of their presentation on the interview process. They gave some good information about how they actually go about interviews.

Industry Leaders’ Feedback:

I thought that the event was great! I hope that the students enjoyed it as much as I did. I look forward to participating next year. Thanks for the opportunity!

I thought this year was more interesting than last year, but I'm not really sure why... It seems that there wasn't as much repeated information this time around. That is to say, one person didn't repeat the comments of 
another _that_ much. If I recall, last year was a bit repetitive. Overall, the format of the event worked for me.

I wish that I would have gone to something like this when I was in school!

\section{The Job-Shadow Day}

The Job-Shadow Day is an important component of the Advisory Board's contribution to enriching the education process. On that day, which takes place during the spring semester, many of the students who are close to graduation get the opportunity to actually join the work force in one of the member companies and become part of a team for one day. This experience, short as it may be, helps bring many of the "theoretical" subject matters close to reality.

The students who participate in the Job-Shadow Day are supervised by the company's assigned supervisor, who plans the whole experience to maximize the benefits of the students. For example, Mr. Kevin Reilly, of Highmark Insurance Group, Pittsburgh, PA, initiates the Job-Shadow Day with the participants, by sending a detailed email message, which covers the following topics:

- Welcoming participants to the Highmark JobShadow Day.

- Requesting information from the participants:

o A soft copy of your resume ... to make notes on the actual document and send back to you.

o A brief description of yourself and your ambitions/goals for the future. That is, what exactly is it that you want to do in your career - upon graduation, 5 years from today, 10 years from today. What makes you tick, what are your interests, hobbies, etc.. This does not have to be lengthy. I'd like to share this information with those whom you will be interacting with on Shadow Day. This will allow them to have a better understanding of who you are, your ambitions and goals.

- Providing information to the participants covering directions to Highmark location, parking, car-pooling, dress code, meals during the day, and possible cancellation.

The following are some of the comments made by students who participated in the job-shadow program:

I did not know much about report building and how important it could be for an organization until I saw them develop and use the reports. We saw the SDLC in action from the design stage to the usage stages.
I think job shadowing day was a great idea. I found it very helpful/refreshing to find out that most of the stuff we are learning in class is used in the workplace. I attended Highmark, and all the people that we met were very friendly and were willing to answer any question that we had. One of the most important things that I learned is that it is imperative to know how to work in teams. That is how all of the business was done there. It was also nice to see that once you leave college, you are not done learning.

In conclusion, the experience that I gained from a field experience with Highmark Life and Casualty was invaluable. I was able to make many connections between the text and discussions with Dr. Fergany to the real day-to-day experiences of a Project Manager. It would be my recommendation that all students who take Project Management would engage in a field experience.

\section{The Internship Program:}

Any junior or senior student, whose overall QPA > 2.75 and major QPA > 3.00, may apply for the Internship Program. The actual internship assignment may range from the equivalent of a 3-credit-hour course, to a fulltime, 12-credit-hour course load. The intern may also be compensated during the internship, but the most important benefits are:

- The intern gets the opportunity to compare and contrast the attitudes and responsibilities in an educational environment with the corresponding attitudes and responsibilities in a professional environment.

- The intern gets the opportunity to apply the knowledge acquired in a variety of college courses to solutions of real-life problems encountered in the work place.

- The internship provides the opportunity for an extended interview for a possible fulltime employment later.

Interns are supervised by both the company's assigned intern supervisor and the SRU Computer Science Department's internship coordinator. They both contribute to the evaluation of the interns. By the end of internships, interns are required to submit an Internship Report, which covers the intern's experience, including the company, work assignments, and self performance evaluation. 
Due to a direct connection between the industry leaders and the department, internships have grown over the years. The industry leaders are able to gauge the quality of students and their educational program during their interaction with the undergraduate students. This close interaction contributes to the industry leaders' evaluation and assessment of a student, by the end of internship, and the program of study during the Board of Visitors' meetings.

Events such as the Industry Awareness Night and Job Shadow Day have allowed students to understand what is being expected by industry leaders, which allows students to update their resume and cover letter and also hone their skills to match the requirements.

\section{The Assessment Process}

The Computer Science Department employs an assessment process [1] which revolves around the course outcomes or objectives-the skills or competencies that students should have acquired by the end of the course. The course outcomes are tied to the degree outcomes, which are in turn tied to the university-wide outcomes. The assessment process consists of three assessment tools; each tool contributing the evaluations of one of the main stake holders: students, advisory board, and faculty. The three tools are:

1. Student Surveys, which measure the students' confidence in conducting activities based on the course outcomes;

2. Internship Appraisals, which measure the employers' assessment of the students' skills during the internship period; and

3. Course Embedded Assessments, which are designed by faculty members to measure the students' proficiency of specific course outcomes.

Based on the results of the above three tools of assessment, the faculty and advisory board members engage in discussions, which may lead to curriculum changes. For example, in the academic year 20052006, and as a result of the assessment process, the department decided to increase the breadth of the allied areas of the Information Systems major.

\section{Value of Advisory Boards}

An active advisory board is an asset to an educational institution and plays an important advisory role. An advisory board can further contribute in many additional ways, namely:
- Internships and other short-term training for students;

- Leads into upcoming technology employment opportunities;

- Feedback on the current curriculums and potential changes;

- Creative ideas and involvement in the recruitment of students, in addition to series of lectures for freshmen;

- Give students a view of the skills that the workforce would require; and

- Allow students to interact with industry leaders.

\section{CONCLUSION}

The most important benefits of advisory boards for educational institutions are preparing the students for the professional career and tuning the educational programs to provide the skills for that career. These benefits are realized through the Job-Shadow, Industry Awareness Night and Internship programs, in addition to regular meetings where students take their first steps towards that professional career.

Moreover, an advisory board can provide further contributions, especially as an external professional opinion, which may help reduce or avoid the "turf battles" that may be triggered by recommendations for curriculum changes.

Nevertheless, it is important for the faculty of an educational institution to clearly distinguish between academic education and professional training, as some advisory boards might try and direct the institution towards the latter.

Acknowledgement: The authors are grateful for all the members of the SRU Computer Science Department Advisory Board, first and foremost for their continued active participation, and also for their kind permission to use their names in this paper.

\section{REFERENCES}

1. Whitfield, D., Bailie, F. K. \& Abunawass, A. M. (2007). Assessment and its Role in Accreditation. International Conference on Frontiers in Education of Computer Science and Engineering, July 2007. 